\title{
A COMPARISON BETWEEN SYNTHETIC SPACE ANALYSIS AND INTANGIBLE HERITAGE INVESTIGATION IN URBAN CONSERVATION
}

\author{
N.T. Alkymakchy, E. H. Ismaeel , H. H. Alsoofe \\ Faculty Members, Department of Architecture, College of Engineering, University of Mosul-Iraq, \\ nahithtaha@yahoo.com, emadhanee@yahoo.com, hatamalsoofe@yahoo.com
} KEY WORDS: Space Structural Analysis, Space Syntax, Intangible Heritage, Urban Conservation, Mosul Old City, Urban
renewal.

\begin{abstract}
:
The conservation of intangible heritage in historical regions has recently become a progressively important topic in the international level. Till recently, in the protection process of historical cities, the concentration has been on the tangible cultural heritage, built environment and historical buildings in old districts ; while safeguarding the intangible cultural heritage has been generally neglected. This paper aims at highlighting the significant role of the intangible heritage in the urban renewal policies of old historical districts. It undertakes the conservation and urban renewal activities of Mosul Old City (MOC) as a case study, and it explains that there are broad distinctions in various aspects between space structural analysis and intangible elements investigation, which designates that the intangible elements do not correlate to material or synthetic items within the urban fabric in the same high grade that is associated with the inhabitants memory of the historical area. It emphasizes the importance of the preservation of intangible heritage besides the tangible one in the urban renewal policies.
\end{abstract}

\section{INTRODUCTION}

In urban spaces, the cultural heritage of a community represents more than the aesthetic reminders of previous times, it inserts history into contemporary spaces then assists identifying the spirit and identity of a place. Yet, several histories or collective memories stay alive with physical traces. Due to gentrification, colonization, and exclusionary policies, various societies could not protect properties within their cities, consequently they left no physical remains to denote their memories of the sites where their histories took place. A number of cultural features of communities are presented in other modes such as stories, historical events and cultural activities which are relegated to cultural organizations leading to be incoherent from their environment and losing their importance to share and affect the urban public live. Currently, in the core of old cities, utilizing historic constructions as a variety of facilities including markets, workshops, shops, causes original residents to leave the area, consequently Genius Loci or the spirit of place is neglected. Thus, the historical areas are much more like stages, what to be conserved was just limited to the appearance but not the soul. The imbalance, in fact, reflects the weakness in our system, which, being exclusively concerned with protecting the tangible heritage overlooks the intangible heritage and thus leaves out great many cultural features that are essentially fundamental (Wang, 2008).

\section{RESEARCH PROBLEM AND OBJECTIVE}

Different circumstances in urban renewal projects of historic cities have varied physical, social, and spiritual notions that may produce various imperceptible values which might not be distinguished in a thorough analysis. Therefore, understanding and appreciating the significance of the essence of the urban context and its hidden values, including its spirit, requires an objective assessment and decisions for its conservation and management. The consideration and protection of intangible heritage in a historic city is a difficult issue due to the fact that such a character is mostly formed within tangible features.
The research main question is : do the results of space structural analysis correspond entirely with those achieved from intangible elements investigations, and if not, do the differences have negative impact on the decision-making in the urban renewal policies of the old cities?

The research aims to seriously examine how city heritage planning may contain insufficiently represented histories and intangible heritage through participatory procedures, and to improve a set of recommendations for a more comprehensive heritage preservation and urban renewal approaches. It looks at possibilities to enhance articulating tangible and intangible heritages collectively, in urban spaces; especially, by investigating how intangible heritage can help living history in such spaces.

\section{SPACE STRUCTURAL ANALYSIS}

\subsection{Space Syntax Analysis}

An array of theories and techniques for the analysis of spatial configurations are included in the term Space Syntax. Originally it was conceived by Bill Hillier, Julienne Hanson and colleagues at The Bartlett, University in the late 1970 s to early 1980 s as a tool to help architects simulate the likely social effects of their designs (Hillier,1984). Space Syntax is an important component for planners because it deals with topologically derived configuration and has techniques that allow the environment to be considered as independent variables. Primarily, Syntax is a method of investigating spatial complexes in an attempt to identify its particular structure that resides at the level of the entire configuration. The method is based upon the theory that the form-function relation in buildings and cities passes through the structural properties of its configuration (Hillier,1998).

Space syntax began from the observation that space is the common ground of the physical and social cities. The physical city is a complex pattern of space, while all social activities happen in space. In itself, of course, this leads to an impasse. All social activities leave spatial traces in the form of recursive patterns, but how can these relate to a physical context whose 
essential patterns were in all likelihood laid down long ago, under the influence of quite different social circumstances? On reflection, the radically different rate of change of the physical and social cities seems in itself to forbid anything but a contingent relation between the two (Hillier, 1998).

The general idea is that spaces can be broken down into components, analyzed as networks of choices, then represented as maps and graphs that describe the relative connectivity and integration of those spaces (Hillier,1984). Over the past two decades, space syntax has been proposed as a new computational language to describe spatial patterns of modern cities. Using space syntax principles, human displacement patterns in the city can be analyzed, mainly by considering the degree to which urban spaces are integrated and connected. Many empirical studies have demonstrated the importance of space syntax for the modeling and understanding of urban patterns and structures( Jiang and Claramunt,2002).

According to (Hillier and Penn,2004) and (Ratti,2004) the general Space Syntax analysis techniques of a street network are Integration, Choice and Depth Distance. Integration (as used in this paper) determines how many turns one has to make from a street segment to reach all other street segments in the network, using shortest paths. If the amount of turns required for reaching all segments in the graph is analyzed, then the analysis is said to measure integration at radius ' $n$ '. The first intersecting segment requires only one turn, the second two turns and so on. The street segments that require the least amount of turns to reach all other streets are called 'most integrate'.

\section{INTANGIBLE HERITAGE}

Intangible culture is to historic areas what the soul is to human being, therefore the UNESCO organization defined Intangible Heritage as non-physical heritage, which includes oral traditions, memories, languages, traditional crafts, performing arts or rituals, knowledge systems, values and know-how (UNESCO, 2003). For preservation purposes, sites are typically identified as physical morphological structures, consisting of frameworks and elements (Markeviciene, 2008). The Quebec Declaration states that 'Heritage is a broad concept and includes the natural as well as the cultural environment. It encompasses landscapes, historic places, sites and built environments, as well as biodiversity, collections, past and continuing cultural practices, knowledge and living experiences' (The Quebec Declaration, 2008).

Heritage conservation cannot substitute sustenance of traditional habitats, but it plays a crucial role in safeguarding tangible heritage and this way becomes a cradle for emerging future traditions (Markeviciene, 2008). The determinant character of a historic area can assert itself as its intangible value which is the spirit of it. Any tangible culture must be supported by intangible value and any intangible culture must rely on the tangible to be visualized. In virtue of the intangible heritage, the historic area will be full of energy, when intangible cultural heritage is carefully conserved, the tangible culture is accordingly conserved. Historic areas are gradually formed because of inhabitant's life. So ,only by keeping and improving the living of the habitants there can the historic areas be conserved effectively (Wang, 2008).

Safeguarding measures to ensure that intangible cultural heritage can be transmitted from one generation to another are considerably different from those required for protecting tangible heritage (natural and cultural). However, some elements of tangible heritage are often associated with intangible cultural heritage. That is why the Convention includes, in its definition of intangible cultural heritage, the instruments, objects, artifacts and cultural spaces associated with it (UNESCO, 2003).

\subsection{History of Intangible Heritage Preservation}

The 16th General Assembly of the ICOMOS (International Council on Monuments and Sites), and more specifically the Youth Forum, the Aboriginal Forum and the Scientific Symposium, have provided an opportunity to further explore the relationship between tangible and intangible heritage, and the internal social and cultural mechanisms of the spirit of place. Spirit of place is defined as the tangible (Buildings, Sites, Landscapes, Routes, Objects) and the intangible elements (Memories, Narratives, Written Documents, Rituals, Festivals, Traditional Knowledge, Values, Textures, Colors, Odors, etc.), that is to say the physical and the spiritual elements that give meaning, value, emotion and mystery to place.

According to Norberg Schulz, the genius loci is the spirit or essence that gives life to people and animates place. In his book, genius loci is described as representing the sense people have of a place, understood as the sum of all physical as well as symbolic values in nature and the human environment" (Jiven and Larkham, 2003).

By its distinctive character the place is formed through time, creating the base of both a building and its users. Nevertheless, buildings are constructed out of the "spirit" of place, enhancing the meaning of the place, acting in harmony to produce urban spaces. In this perspective, human beings are responsible for giving "spirit" to place through their touches and their logical experiences between the buildings and the place (Nezih and Güçan,2008). The genius loci is defined, connected, and perpetuated by the memories and cultural meanings embedded in place. Tuan maintains that a sense of place goes beyond aesthetic appreciation - in other words, places are not always comfortable or welcoming (Davis,2007). Returning to R. Nezih the "spirit of place" refers to the understanding of the physical, social, economic, functional and spiritual relations between the three constant parameters, namely circumscriptions-lots and ownership, place and inhabitants" (Nezih and Güçan, 2008).

\subsection{Genius Loci as an Intangible Heritage}

Although Genius Loci has been defined by various disciplines, it is a vague phenomenological concept. The conceptual approach to the meaning of spirit of place emphasizes that it is created through history in a particular place of a town or a city, and requires an individual method of approach in conservation activities (Nezih and Güçan, 2008).

Genius Loci as a term was born in the Nile valley during the Pre-Dynastic period. Lacking the sophistication of modern science, Egyptians characterized the forces of nature as gods. In Roman mythology a genius loci was the protective spirit of a place. This has often been historically envisaged as a guardian animal or a small supernatural being. With the dawn of rationalism, this spiritual meaning of a place has been more and more negated. The modern movement in architecture tried to analyse the site based on scientific parameters and their optimization like sun angles and circulation distances. The fast growth of cities in the last century, which is still continuing today, and the application of the ,'modern formula' quickly resulted in sterile and faceless neighborhoods. First social 


\section{INVESTIGATION IN URBAN CONSERVATION}

problems resulted in high-density poor city quarters, but in fact, the fast growth of the single family houses in the agglomeration also result in places with no identity. The genius loci, which was found in medieval and renaissance cities has been lost! (Vogler and Vittori, 2006).

After the 2002 International Network of Cultural Policy meeting in Cape Town, South Africa and Senegal drafted a report on instruments to safeguard intangible heritage (Deacon et al, 2004). Three relevant findings include giving attention to "traditional and indigenous knowledge", providing communities with economic incentives ideally other than selling cultural commodities, and seeing communities as "mode of creation and transmission of intangible heritage" (Deacon et al, 2004). The report suggests that communities need to be able to protect their intellectual property and improve or retain their socio-economic status (Leung, 2004).

\section{TYPES OF INTANGIBLE HERITAGE}

Intangible heritage essentially has several characteristics to be preserved under the Convention of the UNISCO including being transmitted from generation to generation; being constantly recreated by communities and groups, in response to their environment, interaction with nature, and history; providing communities and groups with a sense of identity and continuity; promoting respect for cultural diversity and human creativity; being compatible with international human rights instruments; and complying with the requirements of mutual respect among communities, and of sustainable development (Legislative Council Secretariat, 2009).

Intangible cultural heritage takes many forms: The Convention explains that it may be expressed in a number of domains, including but not limited to: a. Oral traditions and expressions including language as a vehicle of the intangible cultural heritage; b. Performing arts; c. Social practices, rituals and festive events; d. Knowledge and practice about nature and the universe; e. Traditional craftsmanship including (a) folk literature; (b) folk music; (c) folk dance; (d) traditional drama; (e) quyi or storytelling performances; (f) acrobatics and athletics; (g) folk art; (h) handicraft skills; (i) traditional medicine; and (j) folk customs (minsu) (UNESCO, 2003).

\subsection{Methods of Analysis for the Intangible Heritage}

As indicated by R. Nezih (Nezih and Güçan,2008), there are different methods used in the analysis of urban forms, grouped as methods of urban morphological analyses, architectural and urban design analyses, and urban conservation analyses.

Typo-morphological studies have been used as a design tool throughout history. They deal with the physical and spatial structure of the built environment and are derived from studies of typical spaces and city structures, based on detailed classifications of buildings and open spaces by type "typology". They consider not only the various scales of the built environment, but also characterize the urban form with its inhabitants. As Moudon states, "typo-morphology offers a working definition of space and building type, and serves as a rich launching ground for studying the nature of building design, its relationship to the city, and to the society in which it takes place".

Although these Typo-morphological tools are used rapidly in urban studies, there is a big conflict because of the shortage of such tools in measuring intangible elements. Many studies used social questionnaires or inhabitance interviews to collect data from site during pre-survey phase. The pre-survey includes a comprehensive literature review, during which all graphic, historical, verbal and written documents related to the various aspects of the site are gathered. Then, base maps of various scales and survey sheets related to the buildings and social groups are prepared for the collection of data during the field work. Hence, the maps and data sheets assist in gathering the required information on the general characteristics of the site which will provide a foundation for the subsequent stages.

\section{THE IMPORTANCE OF THE INTANGIBLE HERITAGE}

Eliade points out, that in all cultures, places have had a deeply mythological meaning. The foundation of a house, a settlement or a town has been a religious act, which is still reminiscence today. Architecture has an eminent role as a key interface and definition of our being-in-the-world. Where natural environment is more and more lost, architecture takes a key role in creating places and in the best case a 'genius loci' (Vogler and Vittori, 2006).

The spirit of place offers a more comprehensive understanding of the living and, at the same time, permanent character of monuments, sites and cultural landscapes. It provides a richer, more dynamic, and inclusive vision of cultural heritage. Spirit of place exists, in one form or another, in practically all the cultures of the world, and is constructed by human beings in response to their social needs. The communities that inhabit place, especially when they are traditional societies, should be intimately associated in the safeguarding of its memory, vitality, continuity and spirituality (The Quebec Declaration, 2008).

\section{THE PRACTICAL FRAMEWORK}

The importance of the intangible heritage represented by its elements is recognized, hence, for the research purpose, it is vital to define its main aspects that are included in the concerned area, in order to clarify the impact of the Genius Loci on the developing planning of the urban historic fabric. Therefore, a review on the theoretical study demonstrates these elements as:

- $\quad$ Memories and Commemorations;

- $\quad$ Legend and Narrative;

- $\quad$ Accident, Festival and Ritual;

- $\quad$ Traditional Knowledge, Name and Occupation; and,

- $\quad$ Value, Texture, Colure and Odor

\subsection{The Case Study: Mosul Old City}

In the (MOC) in Iraq, urban tradition is greatly presented as demonstrated by the traditional alleys, houses doorways, the old heritage public buildings, the "Quntara" (covering of the ancient alleys), "Shanasheel" (the upper parts in the traditional houses which are carried by the Kabools), the ornamental elements decorating many interior facades of the heritage houses, as well as many of archaeological components of Assyrian civilization and the ancient city of Nineveh.

For testing the theoretical framework, a part of the historic fabric of (MOC) has been selected, (Fig.1). The case study has been elected due to the variety of its building types and their cultural value; land use; and alleys geometric properties and characteristics. It includes several heritage houses of one of the famous families in Mosul with their supplement services, a number of public buildings like heritage public baths and 
schools, some significant religious building like mosques and churches, and few valuable urban features like alley arches.

In order to recognize the impact of the intangible elements on planning the urban renewal, two procedures have been carried out to derive results for comparison; the space syntax analysis method and the investigations of intangible heritage elements.

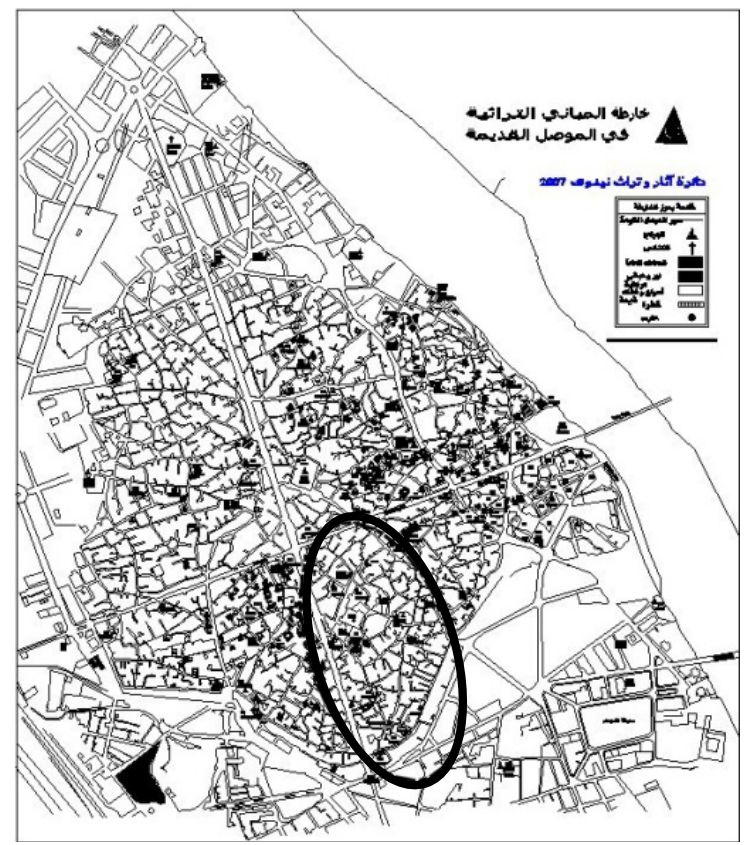

Fig.1: Mosul old city (source: Directorate of Antiquities)

\subsubsection{Space Syntax Analysis}

The first results obtained by the performed techniques are the outcomes of the calculation of space syntax method of the entire concerned site alleys, so as to recognize and identify the high integrated spots of the physical built heritage of the historic fabric. All segments have been numerated, given an identified number and listed in space syntax software with their relations with other fragments, and the calculating command was executed to compute the final results, which determined the integration level of entire alleys of the area. The results show the arrangement of the segments due to their integrity starting by the less value concluding by the higher ones. These values have been inserted on their related alleys in the concerned area map as illustrated in (Fig.2).

\subsubsection{Intangible heritage investigation}

Conversely, for distinguishing the intangible heritage elements and their values, a semi-structured questionnaire (including interview) has been distributed to (140) persons of the area residents and (10) specialists academic lecturers to define, characterize and classify available intangible elements in the related area.

The questions concentrate on two kinds of information. The first type is to mention the significant Memories, Commemoration, Legend, Narrative, Accident, Festival, Ritual, Traditional knowledge, Name, Occupation, Value, Texture, Colure and Odor characteristics of the area; while the second is to draw the image of accessibility by describing how specific known buildings in the core of the area could be accessed from surrounding main streets.
It was noted that there were a number of site related features have been frequented in the answers of the participants. A table of these elements and their frequencies has been created (Table.1) to demonstrate the important ones and to use them in the comparison process. In addition, a map for the locations of these features with series numbers has been indicated and their frequencies have been drawn in order to illustrate their concentrated spots (Fig.3). Each of these features has been mentioned in correlation with one or more intangible elements in the participants answers.

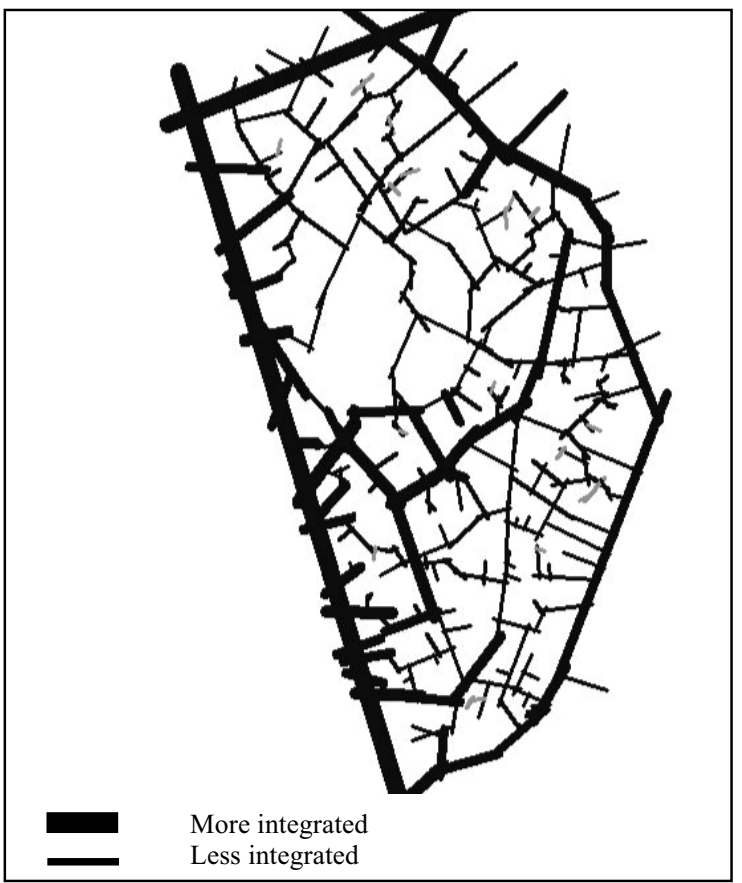

Fig.2: Results of the Space syntax analysis - The level of integration

\begin{tabular}{|c|c|}
\hline No & Freq \\
\hline 1 & 10 \\
\hline 2 & 11 \\
\hline 3 & 10 \\
\hline 4 & 51 \\
\hline 5 & 221 \\
\hline 6 & 92 \\
\hline 7 & 63 \\
\hline 8 & 133 \\
\hline 9 & 34 \\
\hline 10 & 31 \\
\hline 11 & 62 \\
\hline 12 & 32 \\
\hline 13 & 10 \\
\hline 14 & 94 \\
\hline 15 & 40 \\
\hline 16 & 30 \\
\hline 17 & 41 \\
\hline
\end{tabular}

\begin{tabular}{|c|c|}
\hline No. & Freq \\
\hline 18 & 42 \\
\hline 19 & 92 \\
\hline 20 & 93 \\
\hline 21 & 23 \\
\hline 22 & 21 \\
\hline 23 & 10 \\
\hline 24 & 112 \\
\hline 25 & 12 \\
\hline 26 & 132 \\
\hline 27 & 183 \\
\hline 28 & 62 \\
\hline 29 & 85 \\
\hline 30 & 64 \\
\hline 31 & 52 \\
\hline 32 & 25 \\
\hline 33 & 83 \\
\hline 34 & 102 \\
\hline
\end{tabular}

\begin{tabular}{|c|c|}
\hline No. & Freq \\
\hline 35 & 105 \\
\hline 36 & 22 \\
\hline 37 & 103 \\
\hline 38 & 52 \\
\hline 39 & 33 \\
\hline 40 & 142 \\
\hline 41 & 10 \\
\hline 42 & 116 \\
\hline 43 & 63 \\
\hline 44 & 262 \\
\hline 45 & 96 \\
\hline 46 & 145 \\
\hline 47 & 34 \\
\hline 48 & 82 \\
\hline 49 & 14 \\
\hline & \\
\hline & \\
\hline
\end{tabular}

Table.1: The mentioned features and their frequency 


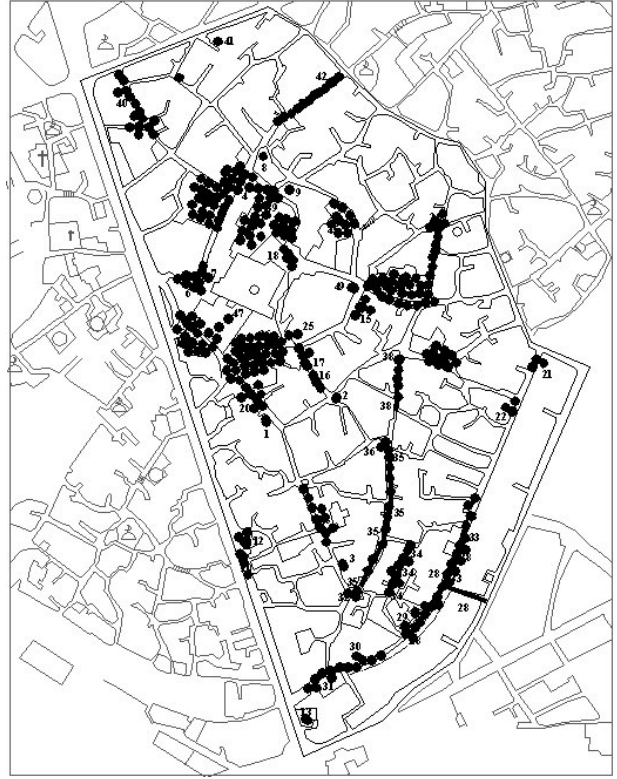

Fig. 3: Illustration of the concentrated spots of the intangible features

\section{DISCUSSION}

By calculating the space syntax analysis, and abstracting the questionnaires data, it can be noticed that:

For the space syntax analysis, there are several routes of high value of integration, in general, those have links with the outer main streets, with few alleys in the core of the concerned area as shown, and, normally, the integrated level gradually reduces when the alleys are more close to the central part. In contrary, for the intangible elements analysis, as frequented features mentioned by the interviewees, in different parts of the case study area, there are high concentration spots(Table.2) distributed accordantly as follows:

- Memories and Commemorations link to public historical events, e.g. (Persian failed attempt to occupy Mosul - Althalma alley, No.33 has been frequented by 83 participants), or to the most famous person and his tomb (Al-Imam Own, No.44 has been frequented by 262 participants).

- Legend and Narrative link to public baths, e.g. (fairies appearing, No.27 has been frequented by 183 participants), and arches of alleys, e.g. (night closure No.6 has been frequented by 92 participants).

- Accident, Festival and Ritual, link to religion construction and spaces, e.g. (Alrabeea alley, No.5 has been frequented 221 participants, Imam Own Alley No.44 has been frequented by 262 participants, Alomaria district No.30 has been frequented by 64 participants,).

- Traditional Knowledge, Name and Occupation link to human skills, e.g. ( Barodjea alley - an alley of small traditional industry of gunpowder, No.35 has been frequented by 105 participants) or as a result of house location of a famous person in the alley (Al-Hamzawia alley, No.38 has been frequented by 52 participants) or for unusual case (Thalath balalee alley-three water channels of three alleys meet in an underground well, No. 24 has been frequented by 112 participants).

- Value, Texture, Colore and Odor link to an alley has a name due to a specific case, e.g. (Al-Qamel (Lice) alley due to its narrow width and it was so dirty at the past, No.34 has been frequented by 102 participants).

\begin{tabular}{|c|c|c|c|c|c|c|}
\hline & $\begin{array}{r}\text { No. } \\
44\end{array}$ & $\begin{array}{c}\text { No. } \\
5\end{array}$ & $\begin{array}{l}\text { No. } \\
27\end{array}$ & $\begin{array}{l}\text { No. } \\
24\end{array}$ & $\begin{array}{l}\text { No. } \\
35\end{array}$ & $\begin{array}{r}\text { No. } \\
34 \\
\end{array}$ \\
\hline $\begin{array}{r}\text { Route } \\
\text { Name }\end{array}$ & 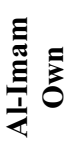 & 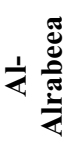 & 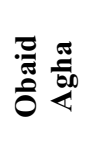 & 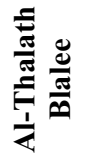 & 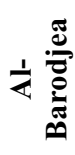 & $\begin{array}{l}\overline{\mathscr{J}} \\
\stackrel{\Xi}{\tilde{O}} \\
\frac{1}{4}\end{array}$ \\
\hline $\begin{array}{c}\text { Memorie, } \\
\text { Commemoration }\end{array}$ & 104 & 96 & 17 & - & 6 & 5 \\
\hline $\begin{array}{l}\text { Legend, } \\
\text { Narrative }\end{array}$ & 28 & - & 148 & 108 & 5 & - \\
\hline $\begin{array}{c}\text { Accident, } \\
\text { Festival, Ritual, }\end{array}$ & 112 & 105 & - & - & 6 & - \\
\hline $\begin{array}{c}\text { Traditional } \\
\text { Knowledge, } \\
\text { Name, } \\
\text { Occupation } \\
\end{array}$ & 18 & 20 & 15 & - & 88 & - \\
\hline $\begin{array}{l}\text { Value, Texture, } \\
\text { Colure, Odor }\end{array}$ & 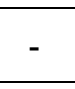 & - & 3 & 4 & 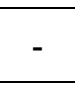 & 97 \\
\hline Frequency & 262 & 221 & 183 & 112 & 105 & 102 \\
\hline
\end{tabular}

Table. 2: Sample of the most intangible elements mentioned in the investigation related to allays

\section{CONCLUSIONS, RECOMMENDATIONS AND INNOVATIONS}

Comparing the final results (Table.3) proves that there are wide differences in many aspects between intangible features analysis and space syntax analysis, which indicates that, within the urban fabric, those intangible elements do not relate to physical or synthetic objects in the same high degree that is related to the sub-community's memory of the inhabitants and users (Fig. 4).

\begin{tabular}{|c|c|c|c|c|c|}
\hline $\begin{array}{c}\text { I.H. } \\
\text { Route } \\
\text { No. }\end{array}$ & $\begin{array}{c}\text { I.H. } \\
\text { Order } / \\
\mathbf{4 9}\end{array}$ & $\begin{array}{c}\text { I.H. } \\
\text { Investigat } \\
\text { ions } \\
\text { Frequenc } \\
\text { y }\end{array}$ & $\begin{array}{c}\text { S.S. } \\
\text { No. }\end{array}$ & $\begin{array}{c}\text { S.S. } \\
\text { Integra } \\
\text { tion } \\
\text { Order } / \\
279\end{array}$ & $\begin{array}{c}\text { S. S. } \\
\text { Integration } \\
\text { Order } \\
\text { Average }\end{array}$ \\
\hline No. 44 & $\mathbf{1}^{\text {st }} / \mathbf{4 9}$ & 262 times & $\begin{array}{c}146 \\
147\end{array}$ & $\begin{array}{c}69^{\text {th }} \\
92^{\text {nd }}\end{array}$ & $\mathbf{8 0 . 5 / 2 7 9}$ \\
\hline No. 5 & $\mathbf{2}^{\text {nd }} / \mathbf{4 9}$ & 221 times & $\begin{array}{c}82 \\
83\end{array}$ & $\begin{array}{c}153^{\text {rd }} \\
167^{\text {th }}\end{array}$ & $\mathbf{1 6 0 / 2 7 9}$ \\
\hline \multirow{2}{*}{ No.27 } & $\mathbf{3}^{\text {rd }} / \mathbf{4 9}$ & 183 times & $\begin{array}{c}163 \\
164 \\
169\end{array}$ & $\begin{array}{c}47^{\text {th }} \\
31^{\text {st }} \\
6^{\text {th }}\end{array}$ & $\mathbf{2 8 / 2 7 9}$ \\
\hline No. 24 & $\mathbf{4}^{\text {th }} / \mathbf{4 9}$ & 112 times & 141 & $39^{\text {th }}$ & $\mathbf{5 0 / 2 7 9}$ \\
\hline No.35 & $\mathbf{5}^{\text {th }} / \mathbf{4 9}$ & 105 times & $\begin{array}{c}244 \\
254\end{array}$ & $\begin{array}{c}66^{\text {th }} \\
78^{\text {th }} \\
40^{\text {th }}\end{array}$ & $\mathbf{6 1 . 3 / 2 7 9}$ \\
\hline No. 34 & $\mathbf{6}^{\text {th }} / \mathbf{4 9}$ & 102 times & 248 & $149^{\text {th }}$ & $\mathbf{1 4 9 / 2 7 9}$ \\
\hline
\end{tabular}

Table. 3: A comparison between Intangible Heritage Investigations and Space Syntax Analysis for sample of alleys

The final results highlight the impossibility of adoption of information derived from physical analysis in the process of developing renewal strategies for the historic cities in isolation of the sub-community contribution in the decision- making on such processes.

Planner awareness for urban intangible aspects plays a vital role in safeguarding any historic fabric, since such an environment has an implicit structured characteristics created by social commensality on various periods and, subsequently, the 
memory of the sub-community that lives within, thus it cannot be ignored or neglected in any urban renewal processes for these sites.

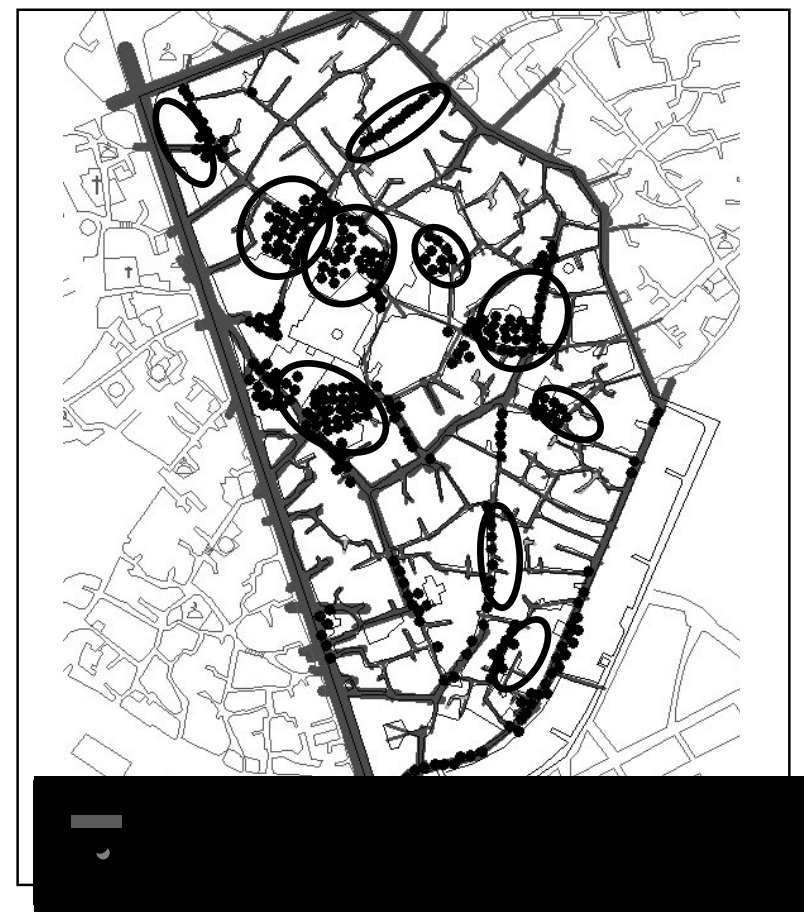

Fig. 4 : Non-correspondence between the Intangible heritage elements and Space syntax analysis

In the historic urban fabric, despite the deep relations among tangible and intangible heritage elements in the residents memory, it does not mean that the intangible ones cannot establish individual memorial structure for its sub-community in a way that it will exist with the destruction of related physical building or alleys.

In most cases, there is a correlation between intangible inhabitants' memory and the built heritage, consequently, any insufficient decision or negative intervention for such features leads to destabilize and threaten these aspects in the memory. Hence, the urban renewal plan should pay attention to this correlation by encouraging and enforcing the useful and essential ones.

\section{REFERENCES}

1. Davis, P. 2007. Ecomuseums and sustainability in Italy, Japan and China: concept adaptation through implementation. In. Knell, S. Macleod S. \& Watson, S, (Eds.) Museum Revolutions: how museums change and are changed, Routledge, London, pp. $198-214$.

2. Deacon, (et al.), 2004. The Subtle Power of Intangible Heritage, Legal and financial instruments for safeguarding intangible heritage, Compiled by the Social Cohesion and Integration Research Programme, HSRC Press, South Africa.

3. Hillier, B. 1999. Space is the Machine: A Configurational Theory of Architecture, Cambridge University Press.

4. Hillier, B. and Hanson J. 1984. The Social Logic of Space, Cambridge University Press.
5. Hillier, B. 1998. "A note on the intuiting of forms: Three issues in the theory of design," Environment and Planning B: Planning and Design (25th anniversary issue), pp 37-40.

6. Hillier, B. and Penn A. 2004 . Rejoinder to Carlo Ratti. Environment and Planning B- Planning and Design, 31(4), pp. 487-499.

7. Jiang, B. and Claramunt C. 2002. Integration of Space Syntax into GIS: New Perspectives for Urban Morphology, Transactions in GIS, 6(3), pp 295-309.

8. Jive'N, G. and Larkham, P. 2003. Sense Of Place, Authenticity And Character, A Commentary Journal Of Urban Design, (8)1, pp.67-81.

9. Legislative Council Secretariat 2009. Intangible cultural heritage, Information Note, Research and Library Services Division, Hong Kong.

10. Markeviciene J. 2008. Genius loci and Homo Faber: A heritage-making dilemma. 16th ICOMOS General Assembly and International Symposium: Finding the spirit of place between the tangible and the intangible, Quebec, Canada.

11. Nezih R. and Güçan N. 2008. Understanding And Preserving Spirit Of Place By An Integrated Methodology In Historical Urban Contexts. In: 16th ICOMOS General Assembly And International Symposium: '29 Sept - 4 Oct, Quebec, Canada.

12. Ratti C. 2004. Space syntax: some inconsistencies. Environment and Planning B - Planning and Design 31(4), pp. 501-511.

13. The Burra Charter 1999. Charter for the Conservation of Places of Cultural Significance. ICOMOS, Australia.

14. The Nara Document 1994. The Nara Document on Authenticity, UNESCO, \& ICCROM, Nara.

15. The Quebec Declaration 2008. The Preservation Of The Spirit Of Place, The 16th ICOMOS General Assembly and International Scientific Symposium, ICOMOS, Quebec, Canada.

16. The Xian Decleration 2005. Monuments and Sites in Their Setting Conserving Cultural Heritage in Changing Townscapes and Landscapes, ICOMOS, Xian.

17. UNESCO 2003. The Convention For The Safeguarding Of The Intangible Cultural Heritage, Paris.

18. Vogler, A. \& Vittori, A. 2006. Genius Loci in the SpaceAge, 1st Infra-Free Life Symposium, Istanbul.

19. Wang, Y. 2008. The conservation of intangible cultural heritage in historic areas, The 16th ICOMOS General Assembly and International Symposium, Quebec, Canada. 